REVESCO. Revista de Estudios Cooperativos ISSN: $1885-8031$

\title{
Cooperación y reciprocidad en la economía colaborativa de Airbnb. Un estudio para la provincia turística de Misiones, Argentina
}

\author{
Juan Antonio Dip ${ }^{1}$; Horacio Simes² y Juan Pablo Benítez ${ }^{3}$
}

Recibido: 23 de noviembre de 2018 / Aceptado: 30 de diciembre de 2019 / Publicado: 22 de junio de 2020

Resumen. Misiones es una de las provincias turísticas de excelencia en Argentina. Allí, empresas convencionales (hoteles y operadores turísticos orientados al mercado) han provistos los servicios turísticos tradicionalmente. Sin embargo, en los últimos años se ha observado un aumento considerable de personas que ven beneficioso compartir temporalmente sus propias casas y habitaciones con turistas de todo el mundo. La llegada de Airbnb ha permitido el encuentro entre pares en un ambiente de intercambio y colaboración bajo una plataforma virtual. Sin embargo, la forma en como está organizada, la cantidad de alojamientos disponibles, precios, sistema de evaluaciones, etc. son desconocidos por los hacedores de políticas (turísticas y fiscales) en la provincia, constituyéndolo en un fenómeno oculto. Por ello, este trabajo expone descriptivamente la composición de Airbnb en la provincia turística de Misiones, evalúa (mediante técnicas cuantitativas) la existencia de algún grado de cooperación y reciprocidad en el vínculo huésped-anfitrión para finalmente exteriorizar algunos puntos debatibles de la plataforma. Se encontró que la evaluación otorgada por el huésped respecto a la ubicación, la cantidad de habitaciones, el tipo de alojamiento, la política de cancelación y la evaluación global del anfitrión, afectan al precio del alojamiento. Preocuparse por la respuesta a consultas de los huéspedes junto a menores restricciones, afectan positivamente la calificación del anfitrión. La falta de transparencia en la dinámica financiera del dinero que recibe la plataforma por parte de los huéspedes, la tasa de ganancia de esta y su relación con la ganancia del propietario son puntos que se deben estudiar más en profundidad. En Argentina, el análisis de la plataforma Airbnb es exiguo y por ello, este trabajo es uno de los primeros en realizar un estudio bajo este esquema y temática.

Palabras clave: P2P; Cooperativismo de plataforma; Intercambio; Políticas Públicas; Turismo.

Claves Econlit: A12; B55; C10; D23; L1.

\section{[en] Cooperation and reciprocity in the sharing economy of Airbnb. A study for the tourist province of Misiones, Argentina}

\begin{abstract}
Misiones is one of the best tourist provinces in Argentina. Conventional companies (hotels and tour operators oriented to the market) have traditionally provided tourist services. In recent years, there has been a considerable increase in people who find beneficial to share their own houses and rooms with tourists from around the world. The arrival of Airbnb has allowed people to match under a virtual platform with a collaboration and exchange feeling. The way in which Airbnb is organized, the amount of available accommodation, prices, the evaluation system, are unknown by policymakers in the province. Hence, it is considered a hidden phenomenon. This paper explains Airbnb's composition in the tourist province of Misiones. By quantitative techniques, we estimate the presence of some cooperation and reciprocity degree in the guest-host link. Finally, we expose some debatable points of this phenomenon. Some results suggest that the evaluation made by the guest about the location, the number of rooms, the type of accommodation, the cancellation policy and the overall evaluation of the host, affect accommodation's price. Host's strive and concern about to guest inquiries, together with fewer restrictions affect positively the host's rating.

The lack of transparency in the financial dynamics of the money between the platform and guests, the profit rate and its relation to the owner's profit, are points that must be researched more in depth. In Argentina, Airbnb's studies are limited, so this paper is one of the first to conduct a research under this scheme and theme.

Keywords: P2P; Cooperative Platform; Exchange; Public Policies; Tourism.
\end{abstract}

Sumario. 1. Introducción. 2. Consideraciones teóricas. 3. Metodología. 4. Resultados. 5. Conclusiones. 6. Referencias bibliográficas.

Cómo citar. Dip, J.A; Simes, H.; Benítez, J.P. (2020) Cooperación y reciprocidad en la economía colaborativa de Airbnb. Un estudio para la provincia turística de Misiones, Argentina. REVESCO. Revista de Estudios Cooperativos, vol. 135 , e69176. https://dx.doi.org/10.5209/reve.69176.

1 Facultad de Ciencias Económicas. Universidad Nacional de Misiones, Argentina. Dirección de correo electrónico: dip@fce.unam.edu.ar

2 Facultad de Ciencias Económicas Universidad Nacional de Misiones, Argentina. Dirección de correo electrónico: hsimes@fce.unam.edu.ar

3 Facultad de Ciencias Económicas. Universidad Nacional de Misiones, Argentina Dirección de correo electrónico: juanbntz17@gmail.com 


\section{Introducción}

La provincia de Misiones se encuentra en el Noreste de la República Argentina. Limita con Brasil y Paraguay. En el mundo es conocida por su atractivo turístico principal: El parque Nacional Iguazú con sus majestuosas cataratas. En el año 2017, visitaron las cataratas del Iguazú un poco más de 1.400.000 turistas. El detalle de su tierra colorada es resaltado en la mayoría de los portales de turismo nacional e internacional, así como su inmensa biodiversidad (la mayor superficie del país). Misiones presenta una riqueza multicultural, gracias al flujo migratorio de inicio del siglo XX proveniente principalmente de Europa. La capital de la provincia es Posadas y es la ciudad con mayor cantidad de habitantes. Además de sus ciudades principales (Puerto Iguazú, Oberá, Eldorado), la provincia se complementa con saltos y cascadas en la mayoría de sus pueblos, siendo los saltos del Moconá los más reconocidos a nivel internacional.

Empresas, como hoteles y operadores turísticos orientados al mercado, son los que han provistos los servicios turísticos tradicionalmente. Sin embargo, en los últimos años se ha observado un aumento considerable de personas que ven beneficioso compartir temporalmente sus propias casas y habitaciones con turistas de todo el mundo. El desarrollo de internet ha permitido la creación de plataformas virtuales para que este intercambio colaborativo entre las personas suceda de manera más fácil.

La situación anterior involucra a lo que se conoce como Economía colaborativa. La misma se refiere a modelos económicos donde se facilita el encuentro o match de personas, en el cual convergen aquellas que poseen bienes que no utilizan o servicios que pueden prestar y aquellas que desean acceder a dichos bienes y/o servicios. Por lo general, existen plataformas virtuales que permiten que los demandantes puedan ubicar a los oferentes. Ejemplos de estas plataformas, tenemos a: Airbnb, Uber, BlaBlacar, crowfunding, entre otros.

Se tiende a englobar dentro del fenómeno de la economía colaborativa a todos aquellos modelos de intercambio económico que responden a tres principios básicos:

- Existe un contacto permanente entre productor y consumidor, hasta el punto de que en muchas ocasiones se fusiona en una única figura.

- Conexión entre iguales sobre una base tecnológica.

- Colaboración inter-partes (García Orois, 2016).

También se refiere a los denominados, Mercados entre pares (peer to peer markets, $P 2 P$ ). Son mercados online que facilitan el encuentro entre oferentes-demandantes de bienes y servicios. Por lo general, los oferentes se constituyen en un grupo pequeño que proveen un exceso de capacidad que de otra manera no se utilizaría, por ello, Airbnb se constituye en uno de los principales P2P de alojamientos del mundo. Está presente en más de 34.000 ciudades, 190 países y por supuesto la provincia de Misiones no escapa a esta realidad en constante crecimiento.

La denominada economía colaborativa ha llegado para quedarse y si bien ha tenido un impacto sumamente positivo en el sector turístico, también ha generado discusiones respecto a lo negativo de su implementación. A favor, se podría decir que se pueden encontrar servicios de mejor calidad a un menor precio comparado con los que ofrecen las empresas tradicionales, y negativamente, se tiene presente la competencia desleal, evasión impositiva, entre otros.

Bajo este contexto, Airbnb (Air bed and breakfast), cuyo significado es cama de aire y desayuno, se creó en el año 2008 como un sitio web (simple directorio) para alquilar habitaciones y apartamentos en la ciudad de San Francisco. Su crecimiento fue exponencial y hoy en día, es una de las principales plataformas de alquiler de alojamientos en todo el mundo. A modo de ejemplo, en una sola noche un millón de personas se hospedan en alojamientos disponibles en la plataforma de Airbnb en 65.000 ciudades alrededor del mundo.

Si bien Misiones es considerada una de las provincias turísticas de excelencia de Argentina, el fenómeno de Airbnb no es conocido ni publicitado masivamente y tampoco es expuesto en las estadísticas públicas. Se ha demostrado que la plataforma tiene muchos impactos positivos en el desarrollo turístico, pero está oculta, es decir no se conoce en números. Un ejemplo de esto puede observarse en las encuestas de ocupación hotelera $(\mathrm{EOH})$ y la denominada Perfil del Turista (PT), realizadas por el Instituto de Estadísticas y Censos de la provincia de Misiones (IPEC), en las cuales no se visualiza explícitamente este tipo de alojamiento a la hora de recolectar de los datos.

En la EOH, el relevamiento se realiza sobre lo que se denomina establecimientos hoteleros: que representa el total de los establecimientos hoteleros y para-hoteleros definidos en (EOH), coordinada por la Secretaría de Turismo de la Nación y el Instituto Nacional de Estadística y Censos (INDEC). Los hoteles se categorizan de acuerdo a la cantidad de estrellas (1-5) y se incluyen apart-hoteles, así como también los hoteles boutiques. Por otro lado, los para-hoteleros por lo general no se categorizan e incluye muchos establecimientos de estancias cortas y de estructura muchas veces más sencillas: albergues, cabañas, bungalows, hospedajes, bed \& breakfast, hosterías, residenciales, etc. La PT se realizó en el 2017 y ha 
cubierto más localidades: Oberá, Aristóbulo del Valle, El Soberbio, Posadas, Iguazú, San Ignacio y Santa Ana. Si bien en la EOH podría resultar comprensible que no se pregunte respecto a hospedajes de este tipo (dada la condición de que se encuentran "ocultos"), en la segunda, se podría ahondar un poco más sobre Airbnb, ya que la misma, en sus resultados menciona que, un 3\% de los turistas utilizó otros tipos de alojamiento en la provincia como departamentos en alquiler y hosterías. Una explicación de esta particularidad e inopia, sería la ausencia de un marco legal que regule a dicha actividad en la provincia de Misiones y a nivel país.

Ante esta carencia de datos y para este trabajo, se obtuvieron los alojamientos disponibles en la plataforma de Airbnb (apartamentos enteros y habitaciones privadas) para la provincia de Misiones en el mes de marzo de 2018. Se recopilaron características según el tipo de alojamiento y se hizo hincapié en recopilar información relacionada con términos que involucren a la economía colaborativa, como ser la reciprocidad. De este modo, si se actúa con espíritu cooperativo, aumenta la reputación y por ende la posibilidad de que emerja la reciprocidad. Por ello, los nuevos mecanismos provistos por la tecnología favorecen la colaboración y hacen visible un modo de actuar (sea como huésped o anfitrión) mediante los denominados ratings o escalas de evaluación.

Si bien Airbnb está catalogada como una economía colaborativa, no está del todo claro si la misma cumple con los requisitos para serla en su totalidad. La idea del trabajo es exponer la discusión de este tema, evaluar (mediante técnicas cuantitativas) si se observa en algún grado la presencia de reciprocidad en el vínculo huésped-anfitrión y exponer descriptivamente la composición del fenómeno Airbnb en la provincia turística de Misiones, Argentina. La importancia de visualizar a Airbnb en números radica en el hecho de tomar conciencia de la presencia de este tipo de alojamientos y en especial para consideración de quienes tienen la potestad en la toma de decisiones de las políticas turísticas y fiscales en una provincia que tiende al turismo sustentable, colaborativo y de excelencia.

\section{Consideraciones Teóricas}

\subsection{Orígenes y conceptualizaciones}

Las actividades enmarcadas dentro de la denominada economía colaborativa tienen un origen reciente en el mundo. Si bien las primeras experiencias pueden datarse en los años noventa del siglo pasado, recién a partir del presente siglo (y principalmente con el inicio de la segunda década del mismo), los emprendimientos adquirieron una importancia y volumen relevantes en muchas economías del mundo. En este recorrido, la economía colaborativa ha ido desempeñando inicialmente un rol marginal y complementario, pero adquiriendo luego un papel destacado a escala global (García Orois, 2016:15).

Entre los primeros estudios que caracterizan y sistematizan las actividades del sector se encuentran las publicaciones de Botsman y Rogers (2010) y Gansky (2010), quienes presentan los aspectos principales de las experiencias y enuncian algunas de las conceptualizaciones más destacadas en el campo. Para una delimitación y clarificación del concepto puede utilizarse la definición de Botsman (2015), de la que se derivan tres características elementales que se encuentran en muchas de las identificaciones del fenómeno:

1. Se trata de un sistema descentralizado de relaciones.

2. Se permite el uso o transferencia de bienes o servicios que se encuentran sub-utilizados, o se les otorga mayor apertura de mercados.

3. Se reemplaza el sistema tradicional de intermediación (encuentro directo entre usuarios a través de la intermediación digital).

Desde una mirada estricta, la economía de colaboración tiene estrecha relación con el encuentro entre pares, comunitario, no oneroso y con el fin puesto en el bien colectivo, vinculándose particularmente con los principios y prácticas propios de la economía social o solidaria. Por otra parte, se observa un análisis más flexible que reconoce la posibilidad de encuentros auto-interesados, con el objetivo puesto en las ganancias que se derivan de un intercambio favorable para las partes y a partir del encuentro de pares. En otro extremo del enfoque vinculado a la economía social o solidaria pueden encontrarse las interacciones de empresas consolidadas que encuentran canales de acceso más masivos y directos a ciertos mercados (lo que implica ir más allá del encuentro de pares), reduciendo costos de transacción y capturando rentas a partir de recursos que se encontraban previamente fuera del mercado. En palabras de Schor (2015: 2): "Un tema central de las críticas es que los capitalistas de riesgo han transformado una práctica progresiva y socialmente transformadora -compartir-, en una práctica amoral y socialmente destructiva buscadora de ganancias".

Por ello, la economía colaborativa se encuentra en la actualidad debatiendo aún su configuración, razón por la cual se observan diferentes denominaciones y diversas caracterizaciones. Entre las múltiples 
denominaciones y conceptualizaciones que ha recibido la economía colaborativa se recogen, entre otras, las siguientes: "economía del compartir" (sharing economy), "economía de plataforma", "economía de acceso", "economía de transferencia" "economía 2P2", "economía 2B2", o "economía bajo demanda" (Selloni, 2017; Petrini, Stedetn de Freitas y Mello da Silveira, 2017). Todas ellas caracterizan algunos rasgos comunes, pero también presentan diferencias. Así, una característica generalizada es que se trata de actividades que difunden ampliamente el uso de bienes o servicios entre partes a través de la intermediación de una plataforma de encuentro (administrada en forma gratuita u onerosa). Además, la mayoría de las experiencias implica la utilización compartida (o la disminución de la subutilización) de recursos de propiedad de una de las partes involucradas, en condiciones que mejoran las del mercado. Por otra parte, entre las diferencias puede destacarse la importancia que se otorga a determinada característica de la operación, ya sea el soporte que facilita la interacción (plataforma digital o no), la posibilidad de uso temporario de un recurso (de acceso) o la transferencia de un bien o servicio (de transferencia), o el tipo de personas que se encuentran (solamente personas físicas -2P2-, o interviene alguna empresa constituida previamente con el objeto del intercambio -2B2-).

En esta dirección, en el análisis de las configuraciones de la economía colaborativa pueden a su vez encontrarse posiciones contrapuestas, en particular entre quienes sostienen una defensa del funcionamiento del sistema de mercados libres y auto-regulados, y quienes promueven la emergencia de formas más solidarias y equitativas de economía. En Scholz (2016) y Díaz Foncea, Marcuello Servós, y Monreal Garrido (2016) (por mencionar algunos estudios) se confrontan los modelos, destacándose las similitudes y diferencias que se observan en los diseños y prácticas. En su mirada crítica, el primer autor destaca la cuestión de la precarización laboral en los siguientes términos: "Usando el lenguaje de la iniciativa empresarial, la flexibilidad, la autonomía, y la elección, la carga de los mayores riesgos de la vida: el desempleo, la enfermedad y la vejez, se han puesto sobre los hombros de los trabajadores" (Scholz, 2016:10). Respecto a la remuneración del trabajo, Scholz (2016) menciona, entre otros, el caso de Amazon Mechanical Turk destacando que: “(...) Trabajadores novatos, a menudo bien formados, se están sacando entre dos y tres dólares por hora en este entorno. Al igual que los trabajadores migrantes o temporeros en la industria de la comida rápida, están trabajando largas horas, están mal pagados y mal tratados por sus jefes virtuales, y obtienen pocos o ningún beneficio" (Scholz, 2016:12). El resultado es la extracción de rentas, y su acumulación, en las sensiblemente menores manos propietarias de las plataformas digitales (Scholz, 2016). Desde la mirada de la gobernanza, Díaz Foncea, Marcuello Servós, y Monreal Garrido (2016) plantean las diferencias que pueden emerger entre un sistema denominado colaborativo y las prácticas efectivas de participación y democracia que puedan observarse, así como el requisito esencial de las empresas solidarias vinculadas con el interés social de la práctica organizacional. Una cuestión no menor en estos modelos se relaciona con la propiedad de la empresa: propiedad común (de los asociados) o privada. Para Díaz Foncea, Marcuello Servós, y Monreal Garrido (2016: 34) los modelos "no son asimilables". Otras miradas críticas destacan la ausencia de legislación laboral e impositiva, o de regulación de la actividad. En ésta última dirección, Goudin (2016) sostiene que para el caso de la Unión Europea ha de mejorarse la legislación vigente.

Finalmente, Scholz (2016) señala que, ante los riesgos visualizados en el denominado "capitalismo de plataforma", se potencia la necesidad de promoción del denominado sistema "cooperativismo de plataforma". Este modelo se asienta en las prácticas del cooperativismo tradicional, haciendo uso de la tecnología digital para extender las relaciones de ayuda mutua, reciprocidad e interés social a los nuevos ámbitos de interacción personal, desplazando el interés por la ganancia por aquél vinculado a la satisfacción de necesidades, y favoreciendo la concreción de resultados económicos más equitativos, sustentables y solidarios. En ésta misma dirección, Selloni (2017) destaca la necesidad de reencontrar el concepto del compartir con nociones como la reciprocidad en sentido estricto, la colaboración y los modelos organizacionales comunitarios.

Gil y Sequera (2018) estudian Airbnb en la ciudad de Madrid. Los autores son críticos al sostener que el servicio de plataforma está controlado por actores económicos profesionales (inmobiliarias etc.), lo que ha desvirtuado el espíritu colaborativo de la plataforma. En consideración, resalta que en los proyectos colaborativos, el bien debe ser temporalmente ocioso. Bajo esta premisa, los alojamientos de Airbnb deberían alquilarse cuando la persona no se encuentre por distintos motivos en el año, por ejemplo en sus vacaciones. Lo anterior no se observa en la práctica, y muy pocos hospedajes cumplen con dicho requisito (Gil, 2018).

Por el lado de quienes resultan más optimistas con el modelo, se encuentran aseveraciones como las de la Cámara Argentina de Comercio y Servicios (2017: 4), desde donde destacan que "(...) La economía colaborativa promueve un consumo más eficiente y moderno, a la vez que permite a los propietarios un mejor aprovechamiento de sus bienes mediante las oportunidades que surgen de la era de la digitalización".

En términos más generales, pueden destacarse las ventajas referidas a la posibilidad de crear o reforzar el capital social, la posibilidad de expandir el consumo a precios más bajos o la expansión de las oportunidades para los microemprendedores (Newlands, Lutz, y Fieseler, 2017). 


\subsection{Airbnb: Su funcionamiento y antecedentes de estudios}

Airbnb pone énfasis en hacer sentir al huésped como en casa en cualquier parte del mundo con su eslogan Welcome home. Se define como un sitio web social para conectar personas que tienen espacio disponible para compartir con aquellos que buscan un lugar para alojarse.

En esta plataforma, se identifican tres partes: un huésped (consumidor), un anfitrión o host (quién pude ser dueño o solo administrador de la propiedad o alojamiento) y el intermediario (plataforma). El anfitrión tiene dos posibilidades a la hora de fijar un precio por el alojamiento que ofrece: asignar un valor arbitrario de acuerdo a sus propios conocimientos o hacer uso de un algoritmo ofrecido por Airbnb denominado precios inteligentes. El algoritmo permite que el precio del alojamiento se adapte automáticamente a los cambios en la demanda y modifica el mismo según la oferta y la demanda que hay en la zona donde está establecida la propiedad, de acuerdo a una fecha específica, las características del alojamiento, entre otros factores. Además del precio que se fija (en cualquiera de las dos modalidades), se le agregan otros adicionales: gastos de limpieza, tarifas por huésped adicional (si correspondiere), tarifa por el costo del servicio de Airbnb y en algunos casos se abona una comisión por cambio de divisa, impuesto al valor agregado e impuestos locales. Los tipos de alojamiento ofrecidos son tres: propiedades enteras (departamentos, casas etc.), habitaciones privadas y habitaciones compartidas dentro de casas o departamentos. En cada uno de ellos, el precio se fija por noche, y en algunos casos existen promociones por estancias largas. Dada las opciones de fijación de precio, es difícil obtener el valor que efectivamente pagaron los huéspedes al momento de hospedarse. Estos últimos eligen su alojamiento de acuerdo a sus necesidades en cuánto a precio, ubicación, comodidades, etc.

Lo más interesante de esta plataforma, es el sistema de evaluaciones que se realizan a doble ciego entre huéspedes y anfitriones. Las evaluaciones sólo pueden realizarlas quienes efectivamente se han hospedado y han sido anfitriones. Cuando el huésped ha salido del alojamiento, dispone de 14 días para evaluar al anfitrión. El anfitrión no podrá ver la evaluación que le ha realizado su huésped hasta que este no haya escrito la suya. Una vez que ambos realizaron las correspondientes evaluaciones, las mismas están disponibles para la lectura de todos los usuarios de la plataforma y estas no pueden modificarse. El sistema es automático y ninguna de las partes tiene injerencia alguna. Es allí, donde las características de reciprocidad pueden manifestarse, pues ninguna de las partes tiene conocimiento de lo que la otra ha escrito y por ende palabras como recomendación, amabilidad o algunos términos de desconformidad pueden emerger.

A nivel internacional, se encuentran antecedentes atrayentes de estudios recientes de Airbnb y su impacto en distintos sectores: turismo, mercado inmobiliario, etc. Liang, Schuckert, Law y Chien Chen (2017) analizan el sistema de evaluación de Airbnb respecto a la característica de superhost que puede lograr el anfitrión. Los anfitriones son evaluados por la plataforma cada tres meses y para llegar a la categoría de superhost, deben tener una valoración general de al menos 4,8 estrellas, responder en menos de $24 \mathrm{hs}$ las consultas en el $90 \%$ de los casos, alojar a huéspedes al menos 10 veces al año y no cancelar ninguna reserva. Los autores encuentran que un alojamiento cuyo anfitrión es superhost es más propenso a recibir mayores calificaciones y los huéspedes son más propensos a elegir alojamientos que tengan anfitriones con esta característica. Esto implicaría, mejores precios para el anfitrión y mayor cantidad de huéspedes alojados.

Boros, Dudás, Kovalcsik, Papp, y Vida (2018), demuestran que la llegada de Airbnb a la ciudad de Budapest ha incrementado los precios de las habitaciones de los hoteles y otros alojamientos de estancias cortas. Resaltan la competencia feroz entre huéspedes que gustan de hoteles y los que gustan de Airbnb al concentrarse todas las opciones dentro del centro de la ciudad. De igual manera, Zervas, Proserpio, y Byers (2017) y Lee (2016) puntualizan que el fenómeno de Airbnb ha provocado la subida del precio de viviendas en las zonas donde se asientan sus alojamientos y que lo mismo ocurre con la disponibilidad y los precios de los alquileres de viviendas para particulares.

Otras investigaciones se concentran en observar el efecto sobre el precio de ciertas características del alojamiento (números de habitaciones, baños, tipo, ubicación), de las evaluaciones recibidas por parte de los huéspedes, del esfuerzo del anfitrión medido a través de distintas variables que figuran en la plataforma: el sistema de políticas de cancelación, nivel de respuestas, tiempo de respuestas, datos socioeconómicos y espaciales (Chen y Xie ,2017; Dogru y Pekin, 2017 y Lorde, 2017). Así, Nicolau y Wang (2017), analizan los determinantes del precio del alojamiento de Airbnb en 33 ciudades. Entre otros atributos, encuentran que el status de superhost, la distancia del alojamiento, ofrecer wifi, cantidad de comentarios en el año, el tipo de cancelación ofrecida, contribuyen a explicar el precio.

Bendickson, Muldoon y Solomon (2017), estudian la sustentabilidad en las economías colaborativas. Los autores enuncian que Airbnb es una alternativa más sostenible comparada con el alojamiento tradicional, ya que el consumo de energía, recursos y la producción de desperdicios es mucho menor.

Falcón Pérez y Fuentes Perdomo (2017), estudian la figura económica que puede facilitar la rehabilitación y el desarrollo urbano de manera sostenible. Dado que las sociedades cooperativas contribuyen a la cohesión 
social, consideran que es la figura más idónea para desarrollar dicha rehabilitación. En este sentido, se podría pensar que cada pueblo o ciudad turística pueda tener una cooperativa local de anfitriones y propietarios de habitaciones, apartamentos, quienes administrarían su propia plataforma. Como ejemplo de lo anterior, se puede mencionar el surgimiento de Fairbnb.coop en 2016 que nace como un movimiento justo y alternativo a las plataformas existentes para compartir el hogar o vacacionar. Conecta a los huéspedes con anfitriones a través de su plataforma, pero distribuye las ganancias y beneficios a comunidades con distintos proyectos sociales.

Reyes Vargas, Ortega Ocaña y Machado Chaviano (2017) presentan un modelo de gestión integrada para el turismo comunitario basado en los principios del cooperativismo para una región de la Amazonía ecuatoriana. Respecto a lo que se refiere a turismo sostenible, los autores resaltan tres dimensiones importantes a tener presente: sostenibilidad económica (rentabilidad y continuidad en el largo plazo), social (respeto de derechos humanos junto al medio ambiente) y ambiental (preservación de ecosistemas). De acuerdo a Airbnb (2014, pag. 4): "Este movimiento no sólo favorece la sostenibilidad fomentando el uso de recursos ya existentes, sino que sirve a personas de todos los niveles socioeconómicos, lo que permite al ciudadano de a pie beneficiarse de nuevas oportunidades". En esta última frase están presentes la sostenibilidad económica y social pero la sostenibilidad ambiental aún no queda muy expuesta.

La reciprocidad es la base de las relaciones e instituciones del capital social. Así, "la cooperación, junto con la confianza y los vínculos de reciprocidad, resulta de la interacción frecuente entre diversas estrategias individuales" (Durston, 2002:19). El autor sostiene que la cooperación se estudia dentro del marco de la Teoría de los Juegos y se fomenta mediante la reiteración de situaciones en las que es posible confiar o traicionar (engañar). Explica la existencia de un círculo vicioso en el cuál la desconfianza es confirmada por el engaño o agresión y esto lleva a rechazar la cooperación. Por otro lado, existe un círculo virtuoso en el cual la confianza o gesto de amistad devuelven actos de igual índole (existe cooperación). Las variables que surgen de aquí tienen la utilidad para entender la dinámica de la retroalimentación de la reciprocidad y la confianza (Durston, 2002).

Siguiendo la lógica anterior, Proserpio, Zervas y Xu (2018) proponen un marco teórico para indagar la evidencia de la reciprocidad en economías colaborativas. El desarrollo teórico es aplicado a datos provenientes de la plataforma Airbnb. Demuestran que los anfitriones que son más recíprocos reciben una mayor calificación (mayores estrellas) y eso se traduce en una posibilidad de mejora del precio para sus alojamientos. Aseguran que la reciprocidad afecta al precio de equilibrio a través de su impacto en los ratings de las evaluaciones, por lo que promover el encuentro de compradores y vendedores e impulsar el comportamiento recíproco juega un rol de suma importancia. Así, la reciprocidad informalmente regula el comportamiento de huéspedes y anfitriones generando cooperación. Se resalta la dificultad de medir la reciprocidad y por ello, la consecuente recurrencia de aproximarla mediante una variable proxy que involucra la longitud de las evaluaciones que realiza el anfitrión a sus huéspedes.

En Argentina, el análisis de la plataforma Airbnb es exiguo y por ello, este trabajo es uno de los primeros en realizar un estudio bajo este esquema y temática. Existen trabajos que muestran generalidades de la economía colaborativa en América Latina, su estructura o la factibilidad de su aplicación (Instituto de la Empresa de Madrid, 2016; Toubes Novoa, 2016; Buenadicha, Cañigueral Bagó y De León, 2017; De Uribe Echevarría, 2017; Lo Bosco, 2017).

Para entender el fenómeno de Airbnb, y en especial en las ciudades o provincias turísticas, es necesario conocer en detalle cómo está compuesto en su totalidad (en el sentido de cantidad de alojamientos, gustos y elecciones de los huéspedes, relación entre calificaciones y el precio, etc.). Conocer en números a un sector del turismo (alojamientos) que se encuentra subrepticio, permitirá dar una idea del potencial de la actividad, la competencia real y, por supuesto, los eventuales impuestos que se podrían recaudar en base a ello. Es decir, exponer una oferta efectiva que involucre no solamente a hoteles, hostales, apart-hotel registrados, sino también a los alojamientos de estancia cortas de Airbnb (que no están registrados). Por otro lado, es importante conocer las relaciones que existen entre el huésped y el anfitrión. Esto permitirá que muchos nuevos anfitriones visualicen lo que la mayoría de los huéspedes eligen o consideran imperioso para sentirse cómodos y elegir un alojamiento, así como también, les permitirá a otros tipos de alojamientos, incorporar nuevos servicios que actualmente no están siendo ofrecidos, pero que los anfitriones de Airbnb sí los ofrecen. Estar al corriente de lo que los huéspedes expresan respecto de los alojamientos y sus anfitriones, es sumamente importante para mejorar la calidad del servicio y por supuesto, mejorar los precios. De hecho, aquellos anfitriones con calificaciones altas, reciben más ofertas por sus anuncios y por ende tienen mayor poder para mejorar sus precios. 


\section{Metodología}

Para determinar la presencia de Airbnb en la provincia de Misiones, se plantearon dos cuestiones a resolver: en primer lugar, extraer los alojamientos de toda la provincia, considerando su composición en términos de prestaciones, la estrecha relación entre huésped-anfitrión, y algunos indicios de reciprocidad. Dentro de esto último podemos citar el uso de palabras que tengan correspondencia con amabilidad, recomendación por el alojamiento, mal trato, engaño entre otras. En segundo lugar y dado que el precio ofrecido se torna sumamente importante, utilizamos el método de precios hedónicos (Rosen, 1974), para determinar que partes (o no) del alojamiento lo afectan. La teoría de demanda de Lancaster (1966), sustento teórico del modelo de Rosen (1974), sugiere que existe un mercado implícito para las características de un bien, en el cual a cada característica se le puede asignar un precio que simboliza la voluntad a pagar del consumidor por la misma. En sí refleja que la utilidad que recibe el consumidor, son los servicios que se derivan de los bienes y no su consumo. Esta teoría inicial sobre la valoración del consumidor de un determinado producto (especialmente heterogéneo), también fue utilizada para la valoración de los hoteles por parte del consumidor. Distintos resultados han demostrado que esta valuación se determina por una amplia gama de atributos específicos del hotel, que incluyen la clasificación de estrellas del hotel, las particularidades de la habitación, la ubicación, la limpieza y las comodidades que ofrece el mismo.

En este sentido, una ecuación de precios hedónicos permite analizar la valoración de los consumidores de ciertas características del bien y determinar en qué medida afectan al precio. Lo ideal es tener un precio de mercado (es decir, el que resulta efectivamente de la transacción entre huésped y anfitrión) más que el ofrecido por el anfitrión, por lo que esto constituye una restricción en nuestro análisis que se debe tener en cuenta al interpretar los resultados. Además, es difícil conocer qué tipo de elección de mecanismo de fijación de precios ha escogido el anfitrión (el algoritmo de precios inteligente, o fijación propia). Lever (2016) asevera que generalmente no es relevante conocer la valoración que hacen los individuos por cada una de las características que ofrece un bien o servicio. Sin embargo, en mercados complejos, toma cierta importancia dada la heterogeneidad de esas características y su fácil diferenciación.

Las variables consideradas en una ecuación hedónica suelen agruparse de la siguiente manera: características inherentes al inmueble, características del vecindario, externalidades presentes en el entorno en que se encuentra el bien raíz, conjunto de parámetros que acompañan a cada atributo y que constituyen los precios implícitos (sombra) de cada característica del inmueble (Lever, 2016).

Dado que Airbnb es un mercado basado en una comunidad de confianza, existe una importante discusión respecto al sesgo de las evaluaciones positivas de los huéspedes. No obstante, se admite que las mismas ayudan a incrementar los ingresos del anfitrión y que se generan, parcialmente, por la naturaleza social de la economía colaborativa (Ert, Fleischer y Magen, 2016).

Además de las características convencionales en un modelo de precios hedónicos, en este trabajo se introducen otras variables que permiten visualizar algún efecto de la amabilidad, colaboración, importancia del género etc., sobre el precio del alojamiento.

Para apreciar los posibles indicios de la reciprocidad presente en una economía colaborativa, se sigue la idea del trabajo de Proserpio, Zervas y Xu (2018) quiénes proponen un marco analítico para medir la reciprocidad en este tipo de economía. Se basan en la longitud de los comentarios que realizan los anfitriones. En este trabajo, se seguirá la lógica inversa, es decir, medir la reciprocidad a través de la longitud de los comentarios que realizan los huéspedes al salir del alojamiento. Se supone que cuanto mayor es la predisposición a escribir por parte de los huéspedes, mayor es la conformidad con el alojamiento, el trato recibido y confianza. Esto se traduce en una mayor cooperación y reciprocidad, por lo que debería visualizarse en una mayor cantidad de estrellas concedidas al anfitrión.

Los métodos estadísticos para aproximar las relaciones planteadas son Mínimos Cuadrados Ordinarios (MCO) y la aplicación del modelo de Tobit para variables dependientes censuradas (para el caso de estimar los efectos de ciertas variables sobre las evaluaciones que obtienen los anfitriones). La distribución de una variable censurada es una mezcla entre una distribución continua y otra discreta. Por lo general, MCO puede producir estimaciones sesgadas e inconsistentes en estos casos. La metodología en detalle puede consultarse en Liang, Schuckert, Law y Chien Chen (2017), Cameron y Trivedi (2010).

\section{Resultados}

\subsection{Análisis descriptivo de alojamientos de Airbnb en Misiones}

Existen distintos portales de internet de donde se pueden extraer los principales datos y características de los anuncios de alojamientos que se ofrecen en la plataforma de Airbnb. También existen recursos de programación computacional para extraer la información que se requiera. Una de las páginas en internet para 
obtener datos es AirDNA. Sin embargo, sólo dispone información de las dos principales ciudades de la provincia de Misiones: Posadas y Puerto Iguazú. Lo mismo ocurre con la encuesta EOH que cubre únicamente estas dos localidades. Según, la EOH y para el año 2017 (último dato disponible), Puerto Iguazú tuvo una ocupación promedio del $53,7 \%$ con 2,9 días de estadía promedio, mientras que Posadas, tuvo un 44,2\% de ocupación promedio y con 1,8 días de estadía promedio. De la encuesta PT, surge que el $32 \%$ de los visitantes optaron por alojarse en establecimientos hoteleros, un $26 \%$ en cabañas, $14 \%$ de los turistas prefirió alojarse en campings, un 7\% en hostel y un 5\% en residenciales. El 3\% restante utilizó otros tipos de alojamiento en la provincia como departamentos en alquiler y hosterías. Ese 3\% podría incluir al fenómeno oculto de Airbnb, pero no se puede afirmar.

A continuación, se muestran los datos obtenidos de AirDNA del mes de agosto de 2018, (extraído en los primeros días de septiembre y según disponibilidad en esa fecha, tabla $\mathrm{N}^{\circ} 1$ ). Los mismos se comparan con la información disponible de otras plataformas de internet de alquiler de alojamientos. Sorprendentemente, la cantidad de alojamientos establecidos en Airbnb, superan a los que aparecen en las plataformas consideradas (tabla $\mathrm{N}^{\circ}$ 2), haciendo la justa aclaración de que no se compara plazas disponibles. Por ello, la importancia de su visibilidad para conocer la oferta efectiva de alojamientos en las ciudades.

Tabla. 1. Alojamientos de Airbnb en Posadas y Puerto Iguazú. Características.

\begin{tabular}{|c|c|c|c|c|c|c|c|}
\hline & & & & \multicolumn{4}{|c|}{ Tipos de Alojamiento } \\
\hline Localidad & $\begin{array}{l}\text { Precio promedio } \\
\text { (U\$) }\end{array}$ & $\begin{array}{c}\text { Tasa de Ocupación } \\
\text { Promedio * }\end{array}$ & $\begin{array}{c}\mathrm{N}^{\circ} \mathrm{de} \\
\text { Alojamientos }\end{array}$ & Entero & $\begin{array}{l}\text { Hab. } \\
\text { Privada }\end{array}$ & $\begin{array}{c}\text { Hab. } \\
\text { Compartida }\end{array}$ & Estudio \\
\hline Posadas & 28 & $38 \%$ & 79 & 40 & 35 & 4 & 18 \\
\hline $\begin{array}{l}\text { Puerto } \\
\text { Iguazú }\end{array}$ & 33 & $42 \%$ & 306 & 167 & 122 & 17 & 7 \\
\hline & \multicolumn{3}{|c|}{ Tamaño de alojamiento } & & & & \\
\hline Localidad & 1 hab. & 2 hab. & 3 hab. O más & Host & \multicolumn{3}{|c|}{ Crecimiento 2011-2018 } \\
\hline Posadas & $43 \%$ & $35 \%$ & $5 \%$ & 112 & \multirow{2}{*}{\multicolumn{3}{|c|}{$\begin{array}{l}140 \% \\
154 \%\end{array}$}} \\
\hline $\begin{array}{l}\text { Puerto } \\
\text { Iguazú }\end{array}$ & $35 \%$ & $49 \%$ & $10 \%$ & 108 & & & \\
\hline
\end{tabular}

Fuente: AirDNA, elaboración propia. * Tasa de ocupación: cantidad de días reservados/cantidad total de días disponibles para reservar el último mes. Agosto 2018.

Tabla. 2. Alojamientos totales de Posadas y Puerto Iguazú. Plataformas de Internet.

\begin{tabular}{|c|c|c|c|c|c|c|}
\hline Localidad & Booking & Homeaway* & Almundo & Despegar & Couchsurfing & Airbnb \\
\hline Posadas & 47 & 10 & 18 & 24 & 9 & 79 \\
\hline Puerto Iguazú & 303 & 17 & 108 & 148 & 35 & 306 \\
\hline
\end{tabular}

Fuente: Elaboración propia. *Corresponden a habitaciones privadas y huésped con referencias. Para el resto, todo tipo de alojamiento. Agosto 2018.

Para explorar el fenómeno en la provincia de Misiones, se procedió a extraer los datos para todos los alojamientos disponibles (enteros y habitaciones privadas) en el mes de marzo de 2018. Se obtuvo información respecto al tipo de alojamiento, instalaciones, anfitrión, comentarios/evaluaciones y palabras que involucren la reciprocidad entre huésped - anfitrión. La búsqueda se concentró en una estancia corta disponible de una noche para 2 personas (para tener en cuenta que el alojamiento este activo). Respecto a la exploración, se procedió a visualizar primero todos los alojamientos en el mapa que proporciona la plataforma, ya que, si bien uno puede colocar la localidad, no está delimitada correctamente, y aparecen alojamientos en otros países (Paraguay y Brasil) o que corresponden a otras localidades, por lo que es necesario filtrar los mismos. Por ejemplo, si se coloca la localidad de Posadas, aparecen alojamientos de la ciudad de Encarnación (Paraguay).

Respecto a la cantidad de anuncios de alojamientos en la provincia de Misiones, se obtuvieron un total de 229 (sin incluir las habitaciones compartidas y disponibles al momento de la consulta). Uno podría equiparar 
el alojamiento entero a un apart hotel \& apartamentos y las habitaciones privadas a las que corresponde a un hotel. El 54\% corresponde a anuncios de alojamientos enteros y un $46 \%$ involucran a habitaciones privadas. E1 50\% se encuentra localizado en Puerto Iguazú, la ciudad turística por excelencia, seguida por Posadas con el $17 \%$ y luego por Oberá con un $8 \%$, ambas con numerosos eventos turísticos, académicos, etc. a lo largo del año. La tabla siguiente muestra un resumen por localidades.

Tabla. 3. Alojamientos totales Airbnb por Municipios de Misiones.

\begin{tabular}{|c|c|c|}
\hline Ubicación & Frecuencia Absoluta & Frecuencia Relativa \\
\hline Aristóbulo del Valle & 4 & $2 \%$ \\
\hline Puerto Rico & 5 & $2 \%$ \\
\hline El Soberbio & 9 & $4 \%$ \\
\hline Eldorado & 11 & $5 \%$ \\
\hline Localidades con 3 anuncios o menos (Hab. Privadas y Entero). & 27 & $12 \%$ \\
\hline Oberá & 19 & $8 \%$ \\
\hline Posadas & 40 & $17 \%$ \\
\hline Puerto Iguazú & 114 & $50 \%$ \\
\hline Total & 229 & $100 \%$ \\
\hline
\end{tabular}

Fuente: Elaboración propia. Marzo de 2018.

Las localidades con 3 anuncios o menos corresponden a: Candelaria, Garupá, Jardín América (3), San Ignacio, Leandro N. Alem (2), Cerro Azul, Campo Grande, Santo Pipó, Panambí, Concepción de la Sierra, Montecarlo, Puerto Esperanza, Puerto Libertad, Wanda, Comandante Andresito, Paraje Caburé, Gral. Manuel Belgrano, San Antonio y San Pedro (1). Un dato no menos sugestivo es que, sin tener en cuenta Posadas y Puerto Iguazú, el resto de la provincia acumula aproximadamente el 32,75\% de los alojamientos totales.

Además de lo anterior se han recolectado y construido las siguientes variables para el análisis cuantitativo de los datos mediante MCO y TOBIT:

- $\quad$ Precio por noche para 2 personas en moneda doméstica AR \$ (expresado en logaritmo).

- $\quad$ Número de habitaciones.

- Habitación Privada: variable binaria que toma el valor 1 para anuncios que ofrecen solo habitaciones privadas y 0 si se trata de un alojamiento entero (casa, apartamento etc.)

- $\quad$ Host Mujer: variable binaria que toma valor uno si el anfitrión es una mujer.

- Instalaciones (expresada en logaritmo): resulta de la suma ponderada de la siguiente manera: 0,40Wifi +0,20TV+ 0,10LAV + 0,30xCocinaMicroonda, donde Wifi, TV, LAV (lavarropas), CocinaMicroondas son variables binarias que toman valor 1 si el alojamiento cuenta con alguno de ellos. Se decidió asignar la importancia (pesos) de las instalaciones de acuerdo a los distintos blogs respecto a la valoración que otorgan los huéspedes a las comodidades en los alojamientos ${ }^{4}$.

- Cancelación Estricta: variable binaria que toma 1 si el alojamiento implementa este tipo de cancelación y 0 en otro caso.

- Evaluación global al anfitrión: La plataforma utiliza un sistema de evaluación por estrellas, pudiendo otorgar en cada aspecto desde 1 a 5 estrellas, en unidades de 0,5. Por lo tanto la evaluación presentada es un promedio de lo evaluado por cada uno de los huéspedes, por lo tanto, no es posible conocer la cantidad de estrellas otorgadas por cada uno de ellos individualmente.

- $\quad$ Cantidades de evaluaciones con la que cuenta el anfitrión.

- Ubicación (calificación): cantidad de puntajes otorgado por el huésped en base a la ubicación del alojamiento.

- Ubic1= toma valor 1 si el alojamiento está a menos de $2 \mathrm{~km}$ de distancia de alguna atracción turística específica en el caso de Posadas (Costanera de Posadas) y a menos de $1 \mathrm{~km}$ de distancia en

\footnotetext{
Consultar: $\quad$ a) https://www.guestready.com/blog/airbnb-amenities-tips/

b) https://moneywise.com/a/top-things-guests-want-in-an-airbnb

c) https://www.bu.edu/bhr/2017/06/07/airbnb-guest-pricing-value/
} 
caso de los demás municipios (Por ejemplo, en puerto Iguazú se consideró el Hito de 3 fronteras y costanera) y 0 en otro caso. Las cataratas del Iguazú se encuentran dentro de un parque Nacional, por lo que únicamente se encuentra un sólo hotel inserto en el mismo.

Ubic $2=$ toma el valor 1 si el alojamiento se ubica en el centro de la ciudad y 0 en otro caso. Para ambos casos se delimitó los mapas y se corroboró que no se asignarán dos veces valores en ambas variables de ubicación (es decir que si se encuentra en el centro es porque no se encuentra cerca de una atracción turística específica y viceversa). Además, se recuerda que la ubicación es una aproximación en base al mapa proporcionado por la plataforma.

- Índice de respuesta del anfitrión a cada consulta de los huéspedes. Si responde al $100 \%$ de las consultas toma valor 1 , si lo hace en un $80 \%$ es igual a 0,80 .

- Variable tiempo de respuesta: es ordinal. Si responde en menos de una hora $=1$, en pocas horas $=$ 2 , en el día $=3$, en unos días o más $=4$.

- Cantidad de veces que se observan en los comentarios de los huéspedes las palabras Amable, Recomendable o algo Malo.

- Cantidad de líneas de comentarios totales por anuncio de alojamiento.

En términos generales, se presenta un análisis descriptivo de algunas variables relevantes. El precio promedio por noche de los establecimientos de Airbnb es de AR \$1271 (US\$52) al momento de realizar la consulta en el mes de marzo. Sin embargo, con la devaluación del peso argentino, al mes de agosto, este precio representaría US\$33. Los precios de acuerdo a la ubicación definida por las variables binarias, no presentan mucha variabilidad. La tabla $\mathrm{N}^{\circ} 4$ resume la información.

Tabla. 4. Precio promedios de alojamientos de acuerdo a la ubicación y tipo.

\begin{tabular}{|c|c|c|c|c|}
\hline & & Precio promedio en AR\$ & $\begin{array}{c}\text { Precio promedio en US\$ } \\
\text { (marzo 2018) }\end{array}$ & $\begin{array}{c}\text { Precio promedio en US\$ } \\
\text { (agosto 2018) }\end{array}$ \\
\hline \multirow{2}{*}{$\begin{array}{c}\text { Variable Binaria de } \\
\text { Ubicación }\end{array}$} & 1 & 1249,13 & 52,04 & 32,02 \\
\cline { 2 - 5 } & 2 & 1238,08 & 51,58 & 31,74 \\
\hline \multirow{2}{*}{ Tipo de Alojamiento } & Entera & 1169,81 & 48,70 & 30,76 \\
\cline { 2 - 5 } & Privada & 1360,47 & 56,66 & 35,79 \\
\hline
\end{tabular}

Fuente. Elaboración propia. Marzo 2018.

La tabla $\mathrm{N}^{\circ} 5$ muestra que los anfitriones hombres apenas superan a la cantidad de anfitriones mujeres (poco más del 50\%). Sin embargo, al analizar los comentarios positivos respecto al trato de los anfitriones, las mujeres superan ampliamente a los hombres, con un total de 415 opiniones amables de 671 totales. Es decir, un $61,85 \%$ de los comentarios amables corresponden a anfitriones que son mujeres.

Tabla. 5. Distinción de anfitriones por género y opiniones amables.

\begin{tabular}{|c|c|c|}
\hline Anfitrión & Cantidad & Amable \\
\hline Mujer & 113 & 415 \\
\hline Hombre & 116 & 256 \\
\hline Total & 229 & 671 \\
\hline
\end{tabular}

Fuente. Elaboración propia. Marzo 2018.

El hecho de responder y que esa respuesta sea recibida por el huésped en el menor tiempo posible, muestra un interés real y de ocupación de la tarea del anfitrión. Se espera que aquellos anfitriones que sean propensos a responder más rápido, tengan un interés mayor por el huésped y, en consecuencia, reciban mayor recomendación por parte de estos. Un poco menos del $50 \%$ de los anfitriones responde las consultas en menos de una hora. Descriptivamente, este fenómeno podemos observarlo en la tabla $\mathrm{N}^{\circ} 6$. 
Tabla. 6. Relación entre el tiempo de respuesta y comentarios favorables.

\begin{tabular}{|c|c|c|c|c|}
\hline Tiempo de Respuesta & $\begin{array}{c}\text { Cantidad de } \\
\text { anuncios }\end{array}$ & En \% & $\begin{array}{c}\text { Anuncios con } \\
\text { recomendaciones }\end{array}$ & $\begin{array}{c}\text { Recomendaciones } \\
\text { favorables }\end{array}$ \\
\hline N/D & 34 & 14,85 & 4 & 11 \\
\hline En menos de una hora & 111 & 48,47 & 79 & 513 \\
\hline En pocas horas & 36 & 15,73 & 17 & 54 \\
\hline En el día & 35 & 15,28 & 12 & 65 \\
\hline En unos días o más & 13 & 5,67 & 1 & 645 \\
\hline Total & 229 & & 113 & 2 \\
\hline
\end{tabular}

Fuente. Elaboración propia. Marzo 2018.

De lo anterior se desprende que los anfitriones que han respondido en menos de una hora han sido los que más recomendaciones y comentarios favorables han recibido. En un análisis preliminar podríamos inferir en que el tiempo que tarda en responder un anfitrión ante la consulta de potenciales huéspedes, es un factor categórico al momento de realizar una valoración del servicio recibido.

Las estadísticas descriptivas de las variables utilizadas se muestran a continuación:

Tabla. 7. Estadísticas descriptivas

\begin{tabular}{|c|c|c|}
\hline Variable & Media & Desvío estándar \\
\hline Precio x noche (AR\$) & 1271 & 888,18 \\
\hline Ubicación (evalu) & 1,853 & 2,243 \\
\hline Ubc1 & 0,359 & 0,480 \\
\hline Ubc2 & 0,158 & 0,366 \\
\hline $\mathrm{N}^{\text {o de Habitaciones }}$ & 1,606 & 1,556 \\
\hline Hab. Privada & 0,467 & 0,500 \\
\hline loginstalaci & $-0,312$ & 0,342 \\
\hline Cancelación Estricta & 0,131 & 0,338 \\
\hline Evaluación & 1,786 & 2,150 \\
\hline Cantidad de comentarios (en log) & 2,698 & 1,561 \\
\hline Cantidad de Evaluación & 7,232 & 14,07 \\
\hline Índice de respuesta & 0,767 & 0,384 \\
\hline Tiempo de respuesta (ordinal) & 1,489 & 1,094 \\
\hline Anfitrión mujer & 0,493 & 0,501 \\
\hline
\end{tabular}

Fuente. Elaboración propia. Marzo 2018.

\subsection{Análisis cuantitativo. Estimaciones}

El modelo hedónico estimado expresa al precio en logaritmo y es regresado sobre dos grupos de variables independientes. El primer grupo involucra al alojamiento: número de habitaciones, ubicación, instalaciones y tipo de alojamiento (entero o privada). El segundo grupo de variables tiene en cuenta: el tipo de cancelación ofrecida por el anfitrión, la evaluación otorgada por los huéspedes y se controló por localidades. Se estimaron tres modelos para observar robustez. 
Tabla. 8. Estimación por MCO.

Variable Dependiente

Precio (en logaritmo)

\begin{tabular}{|c|c|c|c|}
\hline & Modelo I & Modelo II & Modelo III \\
\hline \multicolumn{4}{|l|}{$\begin{array}{c}\text { Variables } \\
\text { independientes }\end{array}$} \\
\hline Ubicación (evalu) & $-0,04 * * *$ & $-0,10 * * *$ & $-0,11 * * *$ \\
\hline Ubc1 & 0,03 & 0,05 & 0,06 \\
\hline Ubc2 & $-0,05$ & $-0,05$ & $-0,06$ \\
\hline $\mathrm{N}^{\circ}$ de Habitaciones & 0,04 & $0,04 *$ & $0,04 *$ \\
\hline Hab. Privada & $-0,204 * * *$ & $-0,18 * * *$ & $-0,20 * * *$ \\
\hline log. Instalaciones & $-0,01$ & $-0,04$ & $-0,03$ \\
\hline Cancelación Estricta & $\mathrm{X}$ & $0,288 * *$ & $0,23 * * *$ \\
\hline Evaluación & $\mathrm{X}$ & 0,07 & $0,08 *$ \\
\hline Control de Localidades & $\mathrm{X}$ & $\mathrm{x}$ & SI \\
\hline R2 ajustado & 0,045 & 0,08 & 0,08 \\
\hline $\mathrm{n}$ & 229 & 229 & 229 \\
\hline Heterocedasticidad & $\mathrm{Si}$ (errores robustos) & No & No \\
\hline FIV (media) & 1,1 & 2,70 & 2,45 \\
\hline Ramsey Reset & $\begin{array}{c}F(3,219)=4 \text { Prob }> \\
F=0,0085\end{array}$ & $\begin{array}{c}\mathrm{F}(3,217)=0,53 \text { Prob }> \\
\mathrm{F}=0,6652\end{array}$ & $\begin{array}{c}\mathrm{F}(3,212)=0,76 \text { Prob }> \\
\mathrm{F}=0,5202\end{array}$ \\
\hline \multicolumn{4}{|c|}{$\begin{array}{l}\text { Aclaraciones } \\
\text { El test para heterocedasticidad es el Breusch-Pagan. La palabra “No“ indica ausencia de Heterocedasticidad. } \\
\text { FIV= Factor de inflación de la varianza. Ningún modelo presentó valores de FIV para las variables independientes } \\
\text { mayores a } 10 . \\
\text { Ramsey Reset -Hipótesis nula: el modelo no posee variables omitidas. }\end{array}$} \\
\hline
\end{tabular}

Fuente. Elaboración propia.

De acuerdo a la tabla anterior, y después de controlar por localidades (modelo III) se percibe que la evaluación otorgada por el huésped respecto a la ubicación afecta al precio del alojamiento (revela sus preferencias hacia alojamientos a los que considera muy bien ubicados). Las variables proxys propuestas para la ubicación de los alojamientos no han resultado significativas (quizás porque se aproximaron de acuerdo al mapa y porque además no existe una diferencia sustancial en el precio). La diferencia en el precio de aquellos anfitriones que ofrecen una cancelación estricta versus otra alternativa más flexible ha resultado positiva y significativa, es decir que políticas de cancelación estricta están relacionadas con mayores precios de los alojamientos. Si bien parece corriente que en otras plataformas la cancelación estricta (relacionada a una política de no reembolso del pago) proporcione precios más bajos, en Airbnb, el hecho de que el huésped busque siempre mayores facilidades, mayor colaboración y menos restricciones, una cancelación estricta no es bien vista, pues implicaría una restricción importante en estas plataformas de economía colaborativa. Esto también se refleja en el hecho de que sólo un $13 \%$ de los alojamientos ofrecen cancelación estricta en Misiones. Dado lo anterior, existirá una tendencia de los huéspedes a buscar alojamientos con cancelaciones más flexibles. Por ejemplo, Liang, Schuckert, Law y Chien Chen (2017) encuentran que cuánto más estricta es la cancelación, menor calificación recibe el anfitrión. Menor calificación implica un menor margen para que el anfitrión pueda mejorar su precio.

Desde un punto de vista del huésped (consumidor) se puede decir que está dispuesto a pagar un poco más de dinero por alojamientos con buena calificación global, con más habitaciones y que el tipo de alojamiento donde vaya a hospedarse sea una propiedad entera. En este sentido Zervas, Proserpio, y Byers (2017) demuestran que las reseñas de los consumidores se convierten en una herramienta importante para que otro 
consumidor descubra, evalúe y compare con otras propiedades. De este modo, el huésped puede comparar alojamientos con características similares pero estar dispuesto a pagar más dinero observando por ejemplo la calificación global que tiene el anfitrión. Los resultados encontrados en este trabajo se asemejan a los de Chen y Xie (2017), Dogru y Pekin (2017) y Lorde (2017).

La presencia de reciprocidad (parcial) se evaluó en un modelo que muestra el efecto de ciertas variables sobre la calificación recibida por el anfitrión. En especial, se presta atención a la cantidad de líneas escritas en los comentarios por parte de los huéspedes. Como se dijo, la reciprocidad informalmente regula el comportamiento de huéspedes y anfitriones generando cooperación. Así, mayor cantidad comentarios (líneas), mayor conformidad con el trato recibido, mayor confianza, mayor reciprocidad, mayor cooperación y por ende una mejor calificación otorgada al anfitrión. El resultado del modelo Tobit es el siguiente:

Tabla. 9. Estimación de Tobit y MCO.

Variable Dependiente

Evaluación (estrellas otorgadas)

\begin{tabular}{|c|c|c|c|c|}
\hline Variables & $\mathrm{MCO}$ & Tobit I & Tobit II & Tobit IIII \\
\hline $\begin{array}{l}\text { Cantidad de líneas en } \\
\text { comentarios (en log) }\end{array}$ & $1,20 * * *$ & $1,27 * * *$ & $1,84 * * *$ & $1,74 * * *$ \\
\hline $\begin{array}{c}\text { Cantidades de } \\
\text { Evaluaciones } \\
\end{array}$ & $-0,03 * * *$ & $\mathrm{X}$ & $-0,06 * * *$ & $-0,07 * * *$ \\
\hline Índice de respuesta & $1,47 * *$ & $\mathrm{X}$ & 1,76 & $2,14 * *$ \\
\hline Tiempo de respuesta & $-0,28^{*}$ & $\mathrm{X}$ & $-0,43$ & $-0,43^{*}$ \\
\hline Anfitrión mujer & $0,53 * *$ & $\mathrm{X}$ & $0,90 * *$ & $0,75^{* *}$ \\
\hline Control de localización & SI & NO & NO & SI \\
\hline $\begin{array}{c}\text { Control de Palabras } \\
\text { (Amable, recomendable, } \\
\text { Malo) } \\
\end{array}$ & SI & NO & SI & SI \\
\hline $\mathrm{n}$ & 113 & 113 & 113 & 113 \\
\hline R2ajustado/ Pseudo R2 & 0,08 & 0,15 & 0,22 & 0,25 \\
\hline $\begin{array}{l}\text { Aclaraciones } \\
\text { Nive } \\
\text { Control de Norma }\end{array}$ & $\begin{array}{l}\text { significan } \\
\text { Heteroce }\end{array}$ & $\begin{array}{l}.10, * * p \\
\text { ad siguie }\end{array}$ & $\begin{array}{l}* * * \mathrm{p}<0.0 \\
\text { ameron } \mathrm{y}\end{array}$ & 010). \\
\hline
\end{tabular}

Fuente. Elaboración propia.

Se observa que la cantidad de líneas en los comentarios produce un efecto positivo sobre la calificación global que recibe el anfitrión. Los huéspedes dedican más tiempo en escribir sus comentarios cuando han experimentado una buena relación con el anfitrión, su alojamiento y las experiencias vividas en él. Las cantidades de evaluaciones pueden jugar un papel negativo en el rating (y en el precio) por el hecho de que los anuncios más baratos, tienden a recibir mayores reservas y consecuentemente más evaluaciones (Nicolau y Wang, 2017). El signo y la significatividad de la variable han sido idénticos en los distintos modelos presentados y con cambios sensibles en su magnitud, especialmente en las especificaciones de los modelos de TOBIT. Otros gestos de reciprocidad y cooperación podemos observarlos en la dedicación que posee el anfitrión al responder a los huéspedes tan rápido como sea posible. A medida que responde más tarde a las consultas, el efecto sobre su calificación es negativo. Por otro lado, responder a la mayoría de los huéspedes presenta un efecto positivo sobre las evaluaciones recibidas. Por ello, mayor índice de respuestas mejor es la calificación concedida por el huésped. Los anfitriones responden al 70\% de los huéspedes, en promedio, en la provincia de Misiones. Finalmente, las mujeres anfitrionas son más propensas a recibir una mejor calificación por parte de los huéspedes. El estudio experimental de Dittrich (2015) demuestra que las mujeres son más recíprocas que los hombres, por lo que en este trabajo se estaría manifestando este fenómeno. Así, el estudio de la mujer como anfitrión de esta plataforma y sus múltiples implicancias, puede constituirse como investigación futura.

El análisis descriptivo ha permitido visualizar el gran número de alojamientos disponibles en la provincia de Misiones en comparación con los disponibles en otras plataformas digitales. El caso de Puerto Iguazú, la 
ciudad turística por excelencia, es destacable. De acuerdo a la tabla $\mathrm{N}^{\circ} 2$, la cantidad de alojamientos disponibles en Airbnb, supera a su competidor más próximo (Booking). Esto tiene una implicancia directa en el cobro de la tasa eco turística, creada en diciembre de 2015 y en plena vigencia en la ciudad. En un inicio, la tasa fue cobrada a todos aquellos turistas que ingresaban por vía terrestre o aérea a la ciudad y participaban de espectáculos naturales, culturales y deportivos. Desde junio de 2017, la misma se extendió hacia los hoteles, albergues o campings y consiste en un pago aproximado de US\$ 1,50 por noche (hasta un máximo de 2 noches) a extranjeros y nacionales. De esta manera, al no estar manifiestos los alojamientos de Airbnb, toda esta recaudación se deja de percibir.

Una solución viable que se puede formalizar, es lo realizado por la comunidad de Andalucía, en España. Airbnb creó un protocolo para que los anfitriones cumplan con la normativa vigente y puedan obtener un número de registro como alojamiento turístico. La misma requiere que las viviendas que tengan un fin turístico, se inscriban en el Registro de Turismo de Andalucía a través de una declaración ante la Consejería de Turismo y Deporte, con la obligatoriedad de que si se promociona la vivienda, la misma deba exhibir su número de registro. Recientemente, Airbnb alertó a todos los anfitriones a registrarse de forma imperativa bajo apercibimiento de quitarlos de su plataforma online. La creación de un registro como el de la comunidad de Andalucía, permitiría recaudar en forma automática la tasa eco turística en Puerto Iguazú y además la plataforma tiene conocimiento del mecanismo de implementación, pues lo está realizando exitosamente en Francia.

Por otro lado, lo evaluado en esta sección induce a pensar la existencia de cierta reciprocidad en el mundo de Airbnb. Esto se manifiesta en acciones de los huéspedes y de los anfitriones (comentarios escritos que terminan afectando a las evaluaciones y reflejándose en el precio del alojamiento). Establecimientos tradicionales que prestan un servicio de alojamiento y quisieran asemejarse al ofrecido por Airbnb, deberían tener en cuenta que más restricciones al momento de realizar alguna reserva, alejan al consumidor promedio. Por ejemplo, la libertad de cancelar la reserva en un tiempo prudencial es bien vista por aquellos que se inclinan por esta plataforma colaborativa. Los esfuerzos por complacer a los consumidores (respuesta rápida a las consultas) genera empatía, reflejándose en mejores evaluaciones. Es oportuno destacar que los perfiles de turistas y personas que eligen alojarse en espacios de Airbnb difieren respecto de aquellos que lo hacen en hoteles o establecimientos tradicionales, por ello, si se decide salir a la búsqueda de estos consumidores, es menester conocer lo que buscan y lo que los hace sentir a gusto. El estudio de Guttentag, Smith, Potwarka y Havitz (2018) demuestra que los que eligen Airbnb lo hacen en primer lugar por sus ventajas prácticas (y de costos) y en segundo por su atractivo de vivir ciertas experiencias. Sin embargo, aquellos consumidores con perfil colaborativo son motivados especialmente por la ética que envuelve a la economía colaborativa: interacción con personas locales, y tener vivencias auténticas de la región donde se alojan. Desde este punto de vista, las situaciones en donde el alojamiento se trate de habitaciones privadas (o compartidas), se asemeja en cierta medida al simbolismo de la economía colaborativa, ya que al compartir espacios comunes con el anfitrión y otros usuarios se expone en mayor medida la reciprocidad y cooperación. Para el caso de reservar un alojamiento entero la cooperación se refleja en la preocupación del anfitrión hacia el huésped y la colaboración de este último en el cuidado del mismo, como si fuera su propia residencia.

Si bien, Airbnb es considerada una economía colaborativa, existen algunos puntos grises que no están muy explorados dada la dificultad de visualizarlos, y no han sido estudiados en este trabajo. En primer lugar, hay cuestiones no muy claras respecto a lo que la plataforma realiza cuando recibe el dinero del huésped (al momento de realizar la reserva) y hasta que efectivamente es percibido por el anfitrión. Cuando una persona realiza una reserva, el intermediario (plataforma) retiene el dinero (puede ser un $50 \%$ en los primeros días y luego el resto) y se lo transfiere al anfitrión al momento de que haya finalizado la estadía del huésped, independientemente de si la reserva se haya hecho, 6 meses atrás, o diez días antes. Es decir, existe un tiempo entre el pago del huésped y la efectivización del pago al anfitrión, del cual se desconoce lo que sucede con ese dinero que queda en manos de Airbnb durante todo ese período. Por otro lado, algunos anfitriones solicitan una retención en la tarjeta de crédito para un seguro en caso de daños al inmueble. Ese monto precargado se libera, si el anfitrión no ha hecho ninguna queja formal en los 14 días posteriores a la salida del huésped. A todo esto, se le debe adicionar el hecho de que el intermediario (plataforma) ya cobró una comisión por el servicio prestado.

En segundo lugar, se encuentra el problema derivado de la fiscalización de la actividad. Las autoridades de los distintos países aún no han regulado estas plataformas, o lo han hecho de manera parcial. Dada esta situación, la industria hotelera ha iniciado en varias ciudades litigios por competencia desleal, ya que no sólo no se abonan impuestos nacionales y locales, sino que también, ningún ente controla que se cumplan los estándares de calidad, higiene, servicios, atención etc. Se considera que gran parte de estos anfitriones son free riders, es decir, no pagan impuestos pertinentes y se ven beneficiados por las inversiones del Estado en la industria hotelera y del turismo. Se estima que en Argentina los impuestos abonados por un hotel o alojamiento registrado, representan un $40 \%$ de la tarifa ofrecida. Esto incluye, el impuesto al valor agregado (IVA), impuesto a las ganancias, obra social, convenios colectivos, impuestos municipales, y además los extras que se abonan en términos de derechos de televisación y música. Sin embargo, es preciso aclarar que 
desde marzo de 2018 la Administración Federal de Ingresos Públicos (AFIP), entidad encargada de recaudar impuestos en Argentina, comenzó a retener dinero a los anfitriones de Airbnb en concepto de impuesto a las ganancias. La alícuota fluctúa entre el 6 y el $28 \%$, según el tipo o perfil de contribuyente que posea el anfitrión. A todo lo anterior, se le suman temas de legalidad que no están resueltos: discriminación del huésped (pues el anfitrión puede rechazarlos), precariedad laboral, seguro y beneficios sociales, entre otros.

La visualización del fenómeno Airbnb en números, así como un conocimiento más detallado de las conductas, de los gustos de los huéspedes y anfitriones, ayudará en gran medida a resolver los puntos grises enunciados y a fortalecer a toda la industria del turismo.

\section{Conclusiones}

El estudio de Airbnb y sus diversos impactos en sectores pujante de la economía (turismo, inmobiliario, etc.) se ha tornado importante en los últimos años. El Banco Interamericano de Desarrollo (BID), recientemente ha lanzado una investigación conjunta con Airbnb, para determinar el impacto en las comunidades locales, de quienes comparten su casa y observar tendencias de viaje a lo largo de América Latina y el Caribe.

Esta investigación ha surgido por el interés de apreciar en números el fenómeno de Airbnb en una provincia turística de excelencia, como es el caso de Misiones, Argentina. Si bien es entendible que no sea expuesto en las estadísticas públicas por falta de regulación, la importancia de contar con información cuantitativa radica en el hecho de tomar conciencia de la presencia de este tipo de alojamiento y en especial para quienes tienen la potestad en la toma de decisiones de las políticas turísticas y fiscales.

La cantidad de anuncios de alojamientos en la provincia de Misiones que se extrajeron ha sido de 229 ( $\sin$ incluir las habitaciones compartidas y disponibles al momento de la consulta). El $50 \%$ se encuentra localizado en Puerto Iguazú, la ciudad turística por excelencia, seguida por Posadas, con el $17 \%$ y luego por Oberá con un $8 \%$, ambas con numerosos eventos turísticos, académicos, etc. La cantidad de alojamientos registrados en Airbnb para la ciudad de Puerto Iguazú, supera a su competidor más próximo (Booking).

Se considera que Airbnb es bueno para los consumidores, pues sus precios suelen ser más baratos que un alojamiento de similares características y para el anfitrión pues le permite obtener nuevos y buenos ingresos. Teniendo en cuenta las restricciones de la muestra obtenida y las consideraciones realizadas de acuerdo al sistema de elección de fijación de precios por parte del anfitrión, se estimó un modelo de precios hedónicos en el que se determinó que la evaluación otorgada por el huésped respecto a la ubicación, la cantidad de habitaciones, el tipo de alojamiento, la política de cancelación propuesta y la evaluación global del anfitrión, afectan a dicho precio. Respecto al comportamiento del huésped y su facilidad para comparar distintos tipos de alojamientos, se puede mencionar que tendrá una mayor disposición a pagar un precio mayor por: un alojamiento entero (versus una habitación privada), o con mayor cantidad de habitaciones (mayor comodidad). La evaluación global otorgada al anfitrión es un determinante del precio. Esto es importante para que los anfitriones sepan cómo responderá el huésped potencial a su alojamiento y servicios. Además, ante similares características del alojamiento, la calificación global que posea el anfitrión puede ser contundente para que el huésped decida alojarse o no en el alojamiento en cuestión (independientemente del precio). Cuánto más estricta es la cancelación del alojamiento, menor calificación recibe el anfitrión. De hecho, aquellos anfitriones con calificaciones altas, reciben más ofertas por sus anuncios de parte de los huéspedes y por ende tienen mayor poder para mejorar sus precios. Lo encontrado en el modelo estimado está en línea con investigaciones de otros autores citados.

La presencia de reciprocidad (parcial) se evalúo en un modelo que muestra el efecto de ciertas variables sobre la calificación recibida por el anfitrión. Se encontró que el afán de escribir comentarios por parte del huésped (medido en cantidad de líneas) explica positivamente la evaluación que recibe el anfitrión. Un efecto positivo se encuentra cuando se analiza el esfuerzo por responder consultas a los huéspedes y el tiempo de respuesta que es realizado por el anfitrión. Las mujeres anfitrionas son más propensas a recibir una mejor calificación por parte de los huéspedes. Por ello, se considera que el estudio de la mujer como anfitrión de esta plataforma y sus múltiples implicancias, puede constituirse como investigación futura. Se resaltó la falta de transparencia en la dinámica financiera del dinero que recibe la plataforma por parte de los huéspedes, pues existe un amplio período de tiempo hasta que el dinero es recibido efectivamente por el anfitrión. Por otra parte, no se han analizado cuestiones relativas a la tasa de ganancia de la plataforma y su relación con la ganancia del propietario.

Finalmente, se hace un análisis de cómo revertir algunas cuestiones en materia impositiva, como la implementada en la Comunidad Andalucía y se exponen algunos puntos grises de esta plataforma colaborativa. Si bien, no está del todo claro que Airbnb sea una economía colaborativa en un ciento por ciento, si está en claro que si queremos beneficiarnos de esta forma de intercambio tenemos el deber de realizarla en pro del bien común, para que realmente se considere sostenible y sustentable en el tiempo. 


\section{Referencias bibliográficas}

Airbinb (2014) El impacto del alojamiento compartido en Madrid. Disponible en: https://www.thinktur.org/media/Airbnb_Estudio_impacto_econymico_en_Madrid.pdf.

Airdna (2018) Datos de Airbnb. Disponible en: https://www.airdna.co.

Bendickson, J.; Muldoon J. \& Solomon, S. (2017) The Sharing Economy and Sustainability: A Case for Airbnb. Small Business Institute Journal, $\mathrm{N}^{\circ} 2, \quad$ Vol. 13, pp. 51- $71 . \quad$ Disponible en: https://www.sbij.org/index.php/SBIJ/article/view/265/222.

Boros, L.; Dudás, G.; Kovalcsik, T.; Papp, S. \& Vida, G. (2018) Airbnb in Budapest: Analysing Spatial Patterns and Room Rates of Hotels and Peer-To-Peer Accommodations. GeoJournal of Tourism and Geosites, No 1, Vol. 21, pp. 26-38. Disponible en: http://gtg.webhost.uoradea.ro/PDF/GTG-1-2018/267_Boros.pdf.

Botsman, R. (2015) Defining the Sharing Economy: What is Collaborative consumption-and What isn't?. Blog web. Disponible en: https://www.fastcompany.com/3046119/defining-the-sharing-economy-what-is-collaborativeconsumption-and-what-isnt.

Botsman, R. \& Rogers, R. (2010) What's Mine Is Yours: The Rise of Collaborative Consumption. First Edition. New York, USA: Harper Business. 279 p.

Buenadicha, C.; Cañigueral Bagó, A. Y De León, I. (2017) Retos y posibilidades de la economía colaborativa en América Latina y el Caribe. Banco Interamericano de Desarrollo, documento para discusión $\mathrm{N}^{\circ}$ 518. Disponible en: http://www2.congreso.gob.pe/sicr/cendocbib/con4_uibd.nsf/DBD8E557A15354CD05258146005D2D76/\$FILE/3.1. IFD-DP-Retos-y-posibilidades-de-la-economia-colaborativa-en-America-Latina-y-el-Caribe.pdf.

Cámara Argentina De Comercio Y Servicios (2017) Informe: Economía colaborativa. Disponible en: http://www.cac.com.ar/data/documentos/6_Econom\%C3\%ADa\%20Colaborativa.pdf.

Cameron, A. C. \& Trivedi, J. B. (2010) Microeconometrics using Stata. Revised edition. Second Edition. United State Of America: Stata Press.

Chen, Y. \& Xie, K. (2017) Consumer valuation of Airbnb listings: A hedonic price approach. International Journal of Contemporary Hospitality Management. N ${ }^{o}$ 9, Vol. 29, pp. 2405-2424. DOI: https://doi.org/10.1108/IJCHM-102016-0606.

De Uribe Echevarría, E. (2017) Turismo colaborativo en la ciudad de Bahía Blanca,Tesis de Grado. Universidad Nacional del Sur, Argentina. Disponible http://repositoriodigital.uns.edu.ar/bitstream/123456789/3379/1/Turismo\%20Colaborativo\%20en\%20la\%20ciudad \%20de\%20Bah\%C3\%ADa\%20Blanca.pdf.

Díaz Foncea, M.; Marcuello Servós, C.; Y Monreal Garrido, M. (2016) Economía Social y Economía Colaborativa: encaje y potencialidades. Economía Industrial, $\mathrm{N}^{\circ}$ 402, pp.27-35. Disponible en: https://dialnet.unirioja.es/servlet/articulo?codigo $=5924492$.

Dittrich, M. (2015) Gender differences in trust and reciprocity: evidence from a large-scale experiment with heterogeneous subjects. Applied Economics, No 36, Vol. 47, pp. 3825-3838. DOI: https://doi.org/10.1080/00036846.2015.1019036.

Dogru, T. \& Pekin, O. (2017) What do guests value most in Airbnb accommodations? An application of the hedonic pricing approach. Boston Hospitality Review, $\mathrm{N}^{\mathrm{o}}$ 2, Vol. 5, pp. 1-13. Disponible en: http://www.bu.edu/bhr/files/2017/06/What-do-guests-value-most-in-Airbnb-accommodations An-application-ofthe-hedonic-pricing-approach_Dogru-Pekin.pdf.

Durston, J. (2002) El Capital Social Campesino en la Gestión del Desarrollo Rural. Primera edición. Chile: CEPAL. 156 p. Disponible en: https://repositorio.cepal.org/bitstream/handle/11362/2346/1/S2002033_es.pdf.

Ert, E., Fleischer, A. \& Magen, N. (2016) Trust and reputation in the sharing economy: The role of personal photos on Airbnb. Tourism Management, Vol. 55, pp. 62-73. DOI: https://doi.org/10.1016/j.tourman.2016.01.013.

Falcón Pérez, C.E. y Fuentes Perdomo, J. (2017) La participación de las cooperativas en el desarrollo urbano sostenible. REVESCO. Revista de Estudios Cooperativos, Tercer Cuatrimestre, No 125, pp. 89-108. DOI: http://dx.doi.org/10.5209/REVE.57063.

Gansky, L. (2010) The Mesh: Why the Future of Business is Sharing. First Edition. Londres, UK: Penguin Books Ltd. $256 \mathrm{p}$.

García Orois, J. M. (Coord.) (2016) Informe sobre economía colaborativa. Grupo de Políticas Públicas y Regulación. Colegio Oficial de Ingenieros en Telecomunicación, España. Disponible en: https://www.aeit.es/sites/default/files/migrate/content/downloads/20160608_informe_economia_colaborativa_97204 05c.pdf.

Gil, J. (2018) ¿Cómo regular el hospedaje entre particulares? Criterios de regulación utilizando el caso de Airbnb. En Ana María de la Encarnación (Ed.): La regulación del alojamiento colaborativo. Viviendas de uso turístico y alquiler de corta estancia en el Derecho español. Thompson-Reuters Aranzadi.

Gil, J. y Sequera, J. (2018) Expansión de la ciudad turística y nuevas resistencias. El caso de Airbnb en Madrid. EMPIRIA. Revista de Metodología de Ciencias Sociales. $\mathrm{N}^{\mathrm{o}}$ 41, pp. 15-32. DOI: https://doi.or/empiria.41.2018.22602.

Goudin, P. (2016) The cost of Non-Europe in the Sharing Economy. Economic, Social and Legal Challenges and Opportunities. European Parliament Research Service. DOI: DOI: 10.2861/26238. Disponible en: http://www.europarl.europa.eu/RegData/etudes/STUD/2016/558777/EPRS_STU(2016)558777_EN.pdf.

Guttentag, D., Smith, S., Potwarka, L., \& Havitz, M. (2018) Why Tourists Choose Airbnb: A Motivation-Based Segmentation Study. Journal of Travel Research, $\mathrm{N}^{\mathrm{o}}$ 3, Vol. 57, pp. 342-359. DOI: https://doi.org/10.1177/0047287517696980. 
Instituto de la Empresa de Madrid (2016) Economía Colaborativa en América Latina. IE Business School, Departamento de Comunicación. Disponible en: https://publications.iadb.org/bitstream/handle/11319/7806/Laeconomia-colaborativa-en-America-Latina.pdf.

Instituto Provincial de Estadísticas y Censos (2017) Encuesta de Ocupación Hotelera. $4^{\circ}$ Trimestre 2017. Misiones. Argentina. Disponible en: https://ipecmisiones.org/encuesta/encuesta-de-ocupacion-hotelera-4-trimestre-de-2017/.

Instituto Provincial de Estadísticas y Censos (2017) Estudio del Perfil del Turista Integrado 2017. Misiones. Argentina. Disponible en: https://ipecmisiones.org/dato-estadistico/perfil-del-turista-2017/.

Ke, Q. (2017) Sharing Means Renting: An Entire-marketplace Analysis of Airbnb. Proceedings of WebSci '17, pp. 131-139. DOI: https://doi.org/10.1145/3091478.3091504.

Lancaster, K. J. (1966) A new approach to consumer theory. Journal of Political Economy, No 2, Vol. 74 , pp. $132-157$. Disponible en: https://www.jstor.org/stable/1828835.

Lee, D. (2016) How Airbnb Short-Term Rentals Exacerbate Los Angeles's Affordable Housing Crisis: Analysis and Policy Recommendations. Harvard Law \& Policy Review, Vol. 10, pp. 229-253. Disponible en: http://harvardlpr.com/wp-content/uploads/2016/02/10.1_10_Lee.pdf.

Lever, G. (2016) El Modelo de precios hedónicos. Apunte de cátedra MAES. Disponible en: http://www.ucipfg.com/Repositorio/MAES/PED/Semana4/PreciosHedonicos.pdf.

Liang, S., Schuckert, M., Law, R., \& Chien Chen, C. (2017) Be a "Superhost": The importance of badge systems for peer-to-peer rental accommodations. Tourism Management, Vol. 60, pp. 454-465. DOI: https://doi.org/10.1016/j.tourman.2017.01.007.

Lo Bosco, L. (2017) El paradigma del consumo colaborativo y sus implicancias en las prácticas turísticas. Tesis de Grado, Facultad de Ciencias Económicas y Sociales, Universidad Nacional de Mar del Plata, Argentina. Disponible en: http://nulan.mdp.edu.ar/2729/1/lobosco-2017.pdf.

Lorde, T (2017) Price-setting Behaviour in the TourismSharingEconomy: A Hedonic Price Analysis of Airbnb Listings in the Caribbean. VI Conferencia REDLAS, 21-22 de septiembre de 2017, San José, Costa Rica. Disponible en: http://www.redlas.net/materiali/priloge/slo/3 troy-lorde.pdf.

Municipio de Puerto Iguazú (2015) Tasa Eco Turística Municipal de Puerto Iguazú, Ordenanza No 54/15. Misiones, Argentina. Disponible en http://nm.ips.com.ar/IPS_Municipal_files/files/Ord54_PuertoIguazu.pdf.

Newlands, G.; Lutz, C.; \& Fieseler, C. (2017) Power in the sharing economy. BI Norwegian Business School. Disponible en: http://nm.ips.com.ar/IPS_Municipal_files/files/Ord54_PuertoIguazu.pdf.

Nicolau, J., \& Wang, D. (2017) Price Determinants of Sharing Economy Based Accommodation Rental: A Study of Listings from 33 Cities on Airbnb.com. International Journal of Hospitality Management, Vol. 62, pp. $120-131$. DOI: https://doi.org/10.1016/j.ijhm.2016.12.007.

Petrini, M.; Stedetn De Freitas, C.; \& Mello Da Silveira, L. (2017) A proposal for a typology of sharing economy. RAM. Revista de Administração Mackenzie, N5, Vol. 18, pp.39-62. DOI: http://dx.doi.org/10.1590/167869712017/administracao.v18n5p39-62.

Petropoulos, G. (2017) An economic review of the collaborative economy. Policy Contribution, No5, Bruegel, European Parliament. Disponible en: http://bruegel.org/wp-content/uploads/2017/02/PC-05-2017.pdf.

Proserpio, D.; Xu, M.; \& Zervas, G. (2018) You Get What You Give: Theory and Evidence of Reciprocity in the Sharing Economy. Quantitative Marketing and Economics (en prensa), pp. 1-44. DOI: http://dx.doi.org/10.2139/ssrn.3203144.

Reyes Vargas, M.V.; Ortega Ocaña, A.; Machado Chaviano, E.L. (2017) Modelo para la gestión integrada del turismo comunitario en Ecuador, caso de estudio Pastaza. REVESCO. Revista de Estudios Cooperativos Primer Cuatrimestre, No 123, pp. 250-275. DOI: http://dx.doi.org/10.5209/REVE.53242.

Rosen, S. (1974) Hedonic prices and implicit markets: Product differentiation in pure competition. Journal of Political Economy, № 1, Vol. 82, pp. 34-55.

Scholz, T. (2016) Cooperativismo de plataforma. Desafiando la economía colaborativa corporativa. Barcelona, España: Dimmons. Disponible en: http://dimmons.net/wp-content/uploads/2016/05/maq_TreborScholz_COOP PreF_DP.pdf.

Schor, J. (2015) The Sharing Economy: Reports from Stage One. Boston College. Disponible en: https://www.bc.edu/content/dam/files/schools/cas_sites/sociology/pdf/TheSharingEconomy.pdf.

Selloni, D. (2017) New Forms of Economies: Sharing Economy, Collaborative Consumption, Peer-to-Peer Economy. En: Selloni, D.; CoDesign for Public-Interest Services. Research for Development. Switzerland: Sprinter Cham, pp. 15-26. DOI: https://doi.org/10.1007/978-3-319-53243-1_2.

Toubes Novoa, M. (2016) Turismo colaborativo, una alternativa de hospedaje. Caso de estudio La Plata. Tesis de Grado, Facultad de Ciencias Económicas, Universidad Nacional de La Plata, Argentina. Disponible en: http://catalogo.econo.unlp.edu.ar/meran/opacbusquedasDB.pl?tipoAccion=BUSQUEDA COMBINABLE\&token=\&string=Toubes+Novoa.

Zervas, G., Proserpio, D., and Byers, J. (2017) The rise of the sharing economy: Estimating the impact of Airbnb on the hotel industry. Journal of Marketing Research, No 5, Vol. 54, pp. 687-705. DOI: https://doi.org/10.1509/jmr.15.0204. 